\title{
BK Nephropathy in Renal Transplant Patients with Epididymo-Orchitis
}

\author{
Mastaneh Moghtaderi, ${ }^{1, *}$ Aliasghar Abedzadeh, ${ }^{2}$ and Mahmmad Vasei ${ }^{3}$ \\ ${ }^{1}$ Pediatric Chronic Kidney Disease Research Center, Tehran University of Medical Sciences, Tehran, IR Iran \\ ${ }^{2}$ School of Medicine, Tehran University of Medical Sciences, Tehran, IR Iran \\ ${ }^{3}$ Pediatrics Centre of Excellence, Department of Pediatric Neurology, Children's Medical Centre Hospital, Tehran University of Medical Sciences, Tehran, IR Iran \\ "Corresponding author: Mastaneh Moghtaderi, No. 62, Dr. Gharib St., Azadi Ave., Tehran, IR Iran. Tel: +98-9127183199, E-mail: drmoghtaderi@gmail.com
}

Received 2017 June 23; Accepted 2018 January 21.

\begin{abstract}
The patient was a 10-year-old male that was transplanted six months prior to this study. He was admitted because of epididymoorchitis, pyuria, glucosuria, and rising blood urea nitrogen (BUN) and creatinine (Cr). BK viruria copy number was 50,000,000. In renal biopsy examination, acute cellular rejection was reported. The diagnosis was BK virus epididymo orchitis with BK allograft nephropathy. His treatment was started by discontinuation of tacrolimus and mycophenolate and starting of leflunomide and low dose prednisolone. After improvement of renal dysfunction and BK load, the treatment regimen was changed to cyclosporine and sirolimus. Renal function after the one-year follow up did not change and remained in a good condition.
\end{abstract}

Keywords: BK Nephropathy, Renal Transplant, BK Virus

\section{Background}

BK virus, John Cunningham (JC) virus, and Simian virus 40 belongs to the polyomaviridae family. BK virus (BKV) infection is one of the most prevalent infections in kidney transplanted patients (1). In most cases, the first infection is seen in children in accordance with decreasing of serum antibodies received from the fetal period. Fifty percent of children have antibodies against the BK virus at about 10 years of age yet in adults, it reaches up to $70 \%$. In the past decades, vaccination was the primary cause of exposure to polyomavirus due to unwanted and uncontrollable contamination, yet BK virus transmission route is not clear yet. The BK virus is very difficult to inactivate by ordinary modalities. There may be a latency state of virus in epithelial cells of renal tubules. In $5 \%$ of healthy adults, there may be a non-syptomatic viruria because of a low grade viral replication in renal tubular cells, which can increase up to $60 \%$ if immune system downgrade occurs. In renal transplanted cases there may be $1 \%$ to $10 \%$ polyomavirus nephropathy, which can explain progressive renal function impairment in some of the transplanted cases (2-4). There may be potential risk factors, such as some immunosuppressive drugs (tacrolimus and mycophenolate mofetil), previous history of rejection, male gender, age, ethnicity, HLA mismatched transplant, and BKV antibody state (5).

\section{Case Presentation}

A 10-year-old male with renal dysplasia at birth had been dialyzed for two years with CAPD. He received cadaver kidney transplantation. His renal function was stable for about six months. He received low dose prednisolone, tacrolimus, and mycophenolate. He was admitted due to epididymo orchitis to the nephrology department. Urine culture was negative. In urine analysis, pyuria and glucosuria was detected. Blood Urea Nitrogen (BUN) and creatinine were elevated. He received antibiotic and renal biopsy was performed. Renal pathology showed tubulitis and acute cellular rejection. Inclusion particle of BK was seen in the renal smear. Serum BK virus copy number was 20,000 and BK copy number in urine was 5,000,000. The researchers discontinued tacrolmus and mycophenolate and started loflonamid for about three weeks. Following this treatment BK PCR in the urine sample was negative and virus load in serum decreased to about 1300. Therefore, lofunamid was discontinued and rapamune and cyclosporine were started while continuing low dose prednisolone. Furthermore, BUN and creatinine remained constant. The patient was followed for one year and he had normal renal function at that time. 


\section{Discussion}

There was intermittent reactivation and low level BK viruria in $5 \%$ to $10 \%$ of immunocompetent adults and $20 \%$ to $60 \%$ of immunocompromised individuals (6). There are a few studies on urinary excretion of BKV in immunocompromised settings except for kidney transplantation. In this study, the patients had severe viruria and epididymoorchitis. The researchers were unsure that the BK virus caused epididymo-orchitis, yet renal function deterioration and renal pathology was associated with BK nephropathy that responded very well to the antiviral management. The gold standard for diagnosis of BK virus-associated nephropathy is renal biopsy. Characteristic findings under the light microscope was intra-nuclear basophilic viral inclusions in epithelial cells of the urothelium.

In early stages, there is cytopathic changes with little or no inflammation or tubular atrophy. This stage is called pattern A. In later stages, that is called Pattern B, there is viral cytopathic changes with varying degrees of inflammation, atrophy of tubular cells and fibrosis. Later on, when there was advanced tubular atrophy and fibrosis and changing of the inflammation to the chronic type, characteristic cytopathic changes were less apparent, this stage was called pattern $C$. There may be crescent formation in the glomerulus, ischemic changes of glomerulus and plasma cell rich infiltrate, micro-calcification, and other changes resembling transplant reaction (7). Renal pathology in the current patient showed tubulitis and interstitial inflammation and nuclear inclusions. Histochemical staining for the large T antigen of SV 40 (antiSV40 immunostaining) was positive, which documents BK nephropathy and correlated with the clinical findings. Serum and urine PCR for CMV was negative. Since BK viremia and viruria occur before any histologic changes related to it, it is recommended to screen the transplanted person for BK virus as a routine follow up (8). Prevention and control of immunosuppression induction in transplant recipients is the mainstay to prevent or treat BK virus- induced nephropathy (9). If screening with PCR for BK virus is performed in high risk patients, it could be diagnosed much earlier, and by decreasing immunosuppression level, serious renal damage could be prevented.

\section{Footnote}

Conflict of Interest: No conflict of interest to declare.

\section{References}

1. Burgos D, Jironda C, Martin M, Gonzalez-Molina M, Hernandez D [BK-virus-associated Nephropathy]. Nefrologia. 2010;30(6):613-7. doi: 10.3265/Nefrologia.pre2010.Oct.10587. [PubMed: 21113209].

2. Garces JC. BK Virus-Associated Nephropathy in Kidney Transplant Recipients. Ochsner J. 2010;10(4):245-9. [PubMed: 21603392]. [PubMed Central: PMC3096223].

3. Mengel M, Marwedel M, Radermacher J, Eden G, Schwarz A, Haller H, et al. Incidence of polyomavirus-nephropathy in renal allografts: influence of modern immunosuppressive drugs. Nephrol Dial Transplant. 2003;18(6):1190-6. [PubMed: 12748354].

4. Ginevri F, De Santis R, Comoli P, Pastorino N, Rossi C, Botti G et al. Polyomavirus BK infection in pediatric kidney-allograft recipients: a single-center analysis of incidence, risk factors, and novel therapeutic approaches. Transplantation. 2003;75(8):1266-70. doi:10.1097/01.TP.0000061767.32870.72. [PubMed: 12717214].

5. Smith JM, McDonald RA, Finn LS, Healey PJ, Davis CL, Limaye AP. Polyomavirus nephropathy in pediatric kidney transplant recipients. Am J Transplant. 2004;4(12):2109-17. doi: 10.1111/j.1600-6143.2004.00629.x. [PubMed: 15575916].

6. Gheissari A, Moghim S, Navaie S, Merrikhi A, Madihi Y. BK virus excretion in acquired immunocompromised children: A comparison between kidney transplant recipients and steroid resistant nephrotic syndrome. J Res Med Sci. 2013;18(1):61-4. [PubMed: 23901340]. [PubMed Central: PMC3719230].

7. Garces JC. BK Virus-Associated Nephropathy in Kidney Transplant Recipients. Ochsner J. 2010;10(4):245-9.

8. Hirsch HH, Brennan DC, Drachenberg CB, Ginevri F, Gordon J, Limaye AP, et al. Polyomavirus-associated nephropathy in renal transplantation: interdisciplinary analyses and recommendations. Transplantation. 2005;79(10):1277-86. [PubMed: 15912088].

9. Smith JM, Dharnidharka VR, Talley L, Martz K, McDonald RA. BK virus nephropathy in pediatric renal transplant recipients: an analysis of the North American Pediatric Renal Trials and Collaborative Studies (NAPRTCS) registry. Clin J Am Soc Nephrol. 2007;2(5):1037-42. doi: 10.2215/CJN.04051206. [PubMed: 17702713]. 